Conclusion As older people in Haiti were often the sole carers of under- $5 \mathrm{~s}$, there is a need to recognise their importance in this role and support them within it, allowing them assess to the nutritional services the children in their care so vitally need. More generally, in any emergency setting, organisations need take into account all stakeholders in child nutrition when planning and implementing programmes.

\section{G268(P) ARE ESSENTIAL MEDICINES AVAILABLE, RELIABLE AND AFFORDABLE IN LOW-MIDDLE INCOME COUNTRIES?}

${ }^{1,2}$ TOB Eden, ${ }^{2}$ E Burns, ${ }^{2}$ P Freccero, ${ }^{3} \mathrm{~L}$ Renner. ${ }^{1}$ Academic Unit of Paediatric and Adolescent Oncology, University of Manchester, Manchester, UK; ${ }^{2}$ Programmes Department, World Child Cancer UK, London, UK; ${ }^{3}$ Paediatric Department, Korle Bu Teaching Hospital, Accra, Ghana

\subsection{6/archdischild-2018-rcpch.261}

Background There is increasing anxiety worldwide that the World Health Organisation recommended Essential Medicines may not be universally available,accessible,affordable and of good quality.

Aims/methods We wished to seek the perceptions of 10 lead paediatricians treating children with cancer in 9 low-middle income countries. We used a 17 point semi-structured questionnaire to gather the information. this study involved doctors in Cameroon,Ghana, Malawi,Tanzania,Zambia, Bangladesh,Myanmar, The Philippines,and Colombia. Collectively the centres were seeing overr 2000 new patients annually of whom a median of 65\% (range 5\%-90\%) received 'curative intent' therapy.

Results Only Bangladesh produced any but not all the required cytotoxics. All countries were required to import some or all the medicines.In only 3 countries did the Ministry of Health directly oversee procurement/importation of drugs. In 5 delegated pharmacies or a single hospital was responsible. in Bangladesh there was a free market approach for procurement and importation. Inconsistent supplies were cited by all respondents especially of critical drugs including antibiotics, morphine, 6-mercaptopurine, methotrexate,cytosine, asparaginase, and vincristine. Reasons cited for no-importation were non/or late renewal of licences to import, reluctance to procure low profit or low volume drugs and anxieties regarding importation of opiates. Medicines were imported from a range of countries most commomly from India (7/9) and China (often via India), argentina,Brazil, South Kores, Cyprus and Malaysia. All respondents expressed anxiety about drug quality imported with no International Quality Certification. High rates of treatment refusal/abandonment $(20 \%$ median range $<5 \%-50 \%)$ were most often attributedto non-affordability by parents unless some subsidies were available.

Conclusions From these perceptions there are major obstacles to be overcome to ensure that all children can receive the medicines they need for any chance of cure certainly those living in low-middle income countries. There are challenges at each stage from production to the bedside and only a truly global effort by all interested parties including the WHO and the Pharmaceutical Industry can resolve these issues.

\section{G269(P) INCREASING BURDEN OF THE IMPACT OF CLIMATE CHANGE ON PAEDIATRIC INFECTIOUS DISEASES}

${ }^{1} \mathrm{G}$ Oligbu, ${ }^{2} \mathrm{~A}$ Adepoju. ${ }^{1}$ Paediatric Infectious Diseases Research Group, St George's University of London, UK; ${ }^{2}$ Department of Paediatric and Child Public Health, University College Hospital, Ibadan, Nigeria

\subsection{6/archdischild-2018-rcpch.262}

Introduction Climate change refers to long-term shifts in weather conditions and patterns of extreme weather events, with recent earthquakes, natural disasters, there is epidemic and increase in many paediatric infectious diseases (PID) worldwide, including some newly-circulating ones, such as Zika virus and arbo-viruses in North America and the Caribbean, Ebola and Cholera outbreak in Africa, SIRS in middle east e.t.c. This reflects the combined impacts of rapid demographic, environmental, social, technological and other changes in our ways of living.

Aims We reviewed the available scientific evidences of the impact of recent climate change on PID and also examines the observed and predicted impacts of changes in major climate variables on pathogen, host, and transmission of PID in order to estimate the future burden of infectious diseases on children.

Methods We reviewed published and unpublished literature on climate change and PID. The data were mainly descriptive and we used predictive analytical modelling to assess the future burden.

Findings We observed evidence of associations between climatic conditions and PID in children with different modality of transmission. The responsible agents identified were viruses, bacteria, protozoa and parasites, with various adaptations in the host. Increasing temperature was the most important contributing factor when compared with other natural disasters.

There is a global resurgence of hitherto controlled diseases and the emergence of new ones with redistribution of existing infectious diseases due to an unstable climate. Many of the most common infectious diseases, and particularly those transmitted by vectors, are highly sensitive to climate variation. New and resurgent vector-borne communicable diseases, including arbo-viruses, such as dengue, Zika and Ebola, and malaria are evident widely. Other infectious diseases, such cholera have shown increased outbreaks due to elevated temperature and flooding with the resultant displacement of affected people.

Conclusions Changes in infectious disease transmission patterns are a likely major consequence of climate change. There is need for a better understanding of the causal relationships, in order to predict the future impacts of this on children's health. In addition, paediatrician are likely to see an increasing number of cases due to adverse effects of climate change. An international collaborative effort with an integrated model of care is therefore required.

\section{G270(P) POST-OPERATIVE OUTCOMES OF GAMBIAN CHILDREN AND ADOLESCENTS POST VALVULAR SURGERY FOR RHEUMATIC HEART DISEASE}

${ }^{1,2} \mathrm{~K}$ Martin, ${ }^{1} \mathrm{~K}$ Forrest, ${ }^{1} \mathrm{~L}$ Jaiteh, ${ }^{1} \mathrm{R}$ Maane, ${ }^{1} \mathrm{~S}$ Anderson. ${ }^{1}$ Clinical Services Department, Medical Research Countil Unit The Gambia, Fajara, The Gambia; ${ }^{2}$ Brighton and Sussex University Hospitals NHS Trust, Brighton, UK

10.1136/archdischild-2018-rcpch.263 